\title{
Gender Demographic Targeting in Sponsored Search
}

\author{
Bernard J. Jansen \\ College of Information Sciences and Technology \\ The Pennsylvania State University \\ University Park, Pennsylvania 16802 \\ jjansen@acm.org
}

\section{ABSTRACT}

In this research, we evaluate the effect of gender in analyzing the performance of sponsored search advertising. We examine a log file with data comprised of nearly 7,000,000 records spanning 33 consecutive months of a search engine marketing campaign from a major US retailer. We classify key phrases selected for the campaign with a probability of being targeted for a specific gender and then compare the consumer actions using the critical sponsored search metrics of impressions, clicks, cost-per-click, sales revenue, orders, and items sold. Findings from our analysis show that the gender-orientation of the key phrase is a significant determinant in predicting behaviors and performance, with statistically different consumer behaviors for all attributes as the probability of a male or female keyword phrase changes. However, gender neutral phrases perform the best overall, calling into question the benefits of demographic targeting. Insight from this research could result in sponsored results being more effectively targeted to searchers and potential consumers.

\section{Author Keywords}

Sponsored search, keyword advertising, pay-per-click, PPC, target audience description, gender, gender personalization

\section{ACM Classification Keywords}

J.4 [Social and Behavioral Sciences]: Economics

\section{General Terms}

Economics, Human Factors, Measurement $\mathrm{t}$

\section{INTRODUCTION}

Online shopping is a growing phenomenon, with off-line retailers expanding their business opportunities to the digital marketplace, and the number of online-only sites increases. Already experiencing significant growth, online sales are expected to continue to grow in the coming years [17]. As the Internet marketplace increases, online retailers become more interested in finding ways to leverage the Web to enhance their business, including sponsored search. The challenge that online retailers face is not only getting visitors

Permission to make digital or hard copies of all or part of this work for personal or classroom use is granted without fee provided that copies are not made or distributed for profit or commercial advantage and that copies bear this notice and the full citation on the first page. To copy otherwise, or republish, to post on servers or to redistribute to lists, requires prior specific permission and/or a fee.

CHI 2010, April 10-15, 2010, Atlanta, Georgia, USA.

Copyright 2010 ACM 978-1-60558-929-9/10/04....\$10.00.

\author{
Lauren Solomon \\ College of Communications \\ The Pennsylvania State University \\ University Park, Pennsylvania 16802 \\ sls529psu@gmail.com
}

to their site but also having these potential customers convert (e.g., to make a purchase). By understanding the search behavior of online consumers, these retailers can find opportunities to optimize keyword advertising strategies, such as those in sponsored search campaigns. This effort increasingly requires the understanding of Web demographics.

Gender has emerged as one of the defining demographics on which to focus. Gender is a recurrent determinant in devising marketing and advertising strategies, with electronic commerce research indicating that gender is a key attribute and predictor of intent to purchase. Findings indicate that females have negative views of online shopping [23], although survey data suggests females are as likely as males to purchase online [10].

Unfortunately, there has been very limited published research concerning the effect of gender in evaluating the successes or failures of sponsored search campaigns because companies generally have not published their data and statistics. Consequently, we currently have incomplete insight into how the gender demographics of searchers affect their interaction with this increasingly important segment of Web search engine results and ecommerce.

In this research, we use the real-life online keyword advertising campaign data of a major retailer to examine the differences among gender-oriented searches and their corresponding online consumer behavior. The research goal is to determine whether gender is a factor that online retailers should consider when creating their advertising strategies, with implications for ecommerce personalization.

There are several important sponsored search terms that are frequently used in the industry, which one must have a working knowledge of in order to follow the research presented in this paper. When a sponsored result is displayed on a search engine results page (SERP) in response to a query that matches a given key phrase, this is called an impression. When a searcher clicks on the hyperlink pointing to an advertiser's landing page, this is a click. The search engine bills the advertiser for this click, an amount known as the cost-per-click (CPC). Once at the landing page, if the consumer makes a purchase (a.k.a., places an order), this act is known as a conversion. An order can be composed of one or more items. The sales revenue generated from this conversion can define the value of the customer. 
In the next section, we begin with a brief literature review, outlining the prior work concerning the effect of gender on searching and online purchasing. We then present our research questions and associated hypotheses, with justifications. We present a brief overview of sponsored search, followed by a description of our data and methods of analysis. We then discuss results and implications for advertisers, online advertising platforms, and consumers. We end with directions for future research.

\section{LITERATURE REVIEW}

The theoretical basis for this research is human information processing. Human information processing is the method of acquiring, interpreting, manipulating, storing, retrieving, and classifying recorded information [22, 26]. There are a number of personal factors that influence information processing in an individual, including, economic class, culture, education, and knowledge, and gender [23], which is the factor of interest in this research.

Prior research has identified important gender differences in information processing strategies. Men and women tend to process information stimuli differently, in terms of types of information and levels of elaboration, and hence arrive at different judgments [27]. Meyers-Levy [18] addressed the selectivity hypothesis, which posits that males typically have a "single-focused agentic orientation" [18, p. 529], and employ a single cue or a few cues that lead to a single inference, while females are comprehensive processors who are likely to have a "multi-focused communal orientation", [18, p. 529] that assimilates all available information.

This difference in information processing has been attributed to biological differences [3], in that female and male brains are anatomically different in size and structure, and these differences lead to a behavioral variance in the way each gender thinks, communicates, and even the way that they shop [9]. The specialization of the hemispheres in a male's brain suggests men respond better to the non-verbal reinforcement that complements the verbal aspects of an advertisement [5]. This difference is likely to show through in the search that begins the shopping experience or the search engine query that precedes an online purchase or the advertisement selection that leads them to that decision.

Previous research in the marketing and information searching on marketing communication areas have also provided evidence for gender differences in information processing behavior. Women are more likely than men to perceive favorably promotional emails with hypertext links for additional information [21], and females are more likely than men to engage in effortful elaboration of the interactive presentation of logos, images, and hyperlinks with a diverse range of promotional incentives [20]. It is suggested that females are more susceptible to verbal description in advertising [5], and they are also known to have a higher need for emotion in Internet advertising [17], relative to males.

Concerning information searching, studies have examined the effect of gender on information behavior on the Web, finding significant behavioral gender differences [c.f., 15, 24]. In a study of the use of Google [16], researchers found significant gender findings. Specifically, males had greater average fixation durations on Web documents than females, females had slightly longer queries, and the eye fixations for males were longer. Ibanez, Czermak, and Sutter [11] discovered that gender and task significantly influence different kinds of search behaviors. However, other studies show that men and women do not significantly differ in their online cognitive information needs [c.f., 17]. This could be attributed to the fact that the Internet has become a staple in a majority of our daily lives, so the gender differences are less. However, there has been no work that we could find on gender in the sponsored search area.

With these differences in searching styles, there have been efforts to personalize Web search results for a variety of demographic factors. Personalization [4] is the tailoring of features or information based on a user model with the aim of improving services or the user experience. Like demographic targeting in the marketing area, personalization makes intuitive sense. The book recommendations on Amazon are one example of a successful implementation of personalization, as is spelling suggestions on Web search engines. However, for more complex personalization, the empirical results have been mixed [c.f., 1, 12]. Again, we could locate no prior work on personalization by gender in the sponsored search area.

A literature review of demographic targeting and personalization in human information processing leaves several open questions. Do gender differences affect online searching and purchasing behavior in the sponsored search area? If there are gender differences, what are these differences? What are their effects? Do gender differences affect advertising costs or profits? Do they affect online commercial searching behavior? These are some of the questions that motivate our research?

\section{RESEARCH QUESTION}

Our research question is: Is there a significant difference in the interaction with sponsored results based on gender?

With an understanding of the relationship between gender and consumer behavior, there is an opportunity for online retail businesses to optimize their search engine marketing strategies and personalize to a particular customer. Results from such research can serve a variety of purposes such as ad creation recommendations, valuable query indications (i.e., evidence for higher bids), and research to support the use of more advanced targeted methods. 
However, it is unrealistic to expect online advertisers to know the gender of each individual searcher. Given the focus of sponsored search and information searching on the query, we therefore concentrate on the search phrase. Specifically, we examine the gender orientation of the key phrase that triggers a sponsored search ad. Unlike user profiles of searchers, key phrases are well within the control and data collection of online advertisers and search engines. Therefore, their use in this research has both theoretical importance and practical implications for sponsored search.

Based on our research question and prior work suggesting differences in the information processing of males and females [c.f., 18], our hypotheses are:

Hypothesis 01: There will be a significant difference between females and males in the number of impressions based on the gender-orientation of the query.

A key metric in any keyword advertising campaign is impressions (i.e., the number of times that a given advertisement appears on a SERP in response to a query submitted by a potential consumer). Analyzing the occurrence of impression would shed light on the gender differences in terms of frequency of ecommerce searching.

Hypothesis 02: There will be a significant difference between females and males in the number of clicks based on the gender-orientation of the query.

The goal of most keyword advertising campaigns is to get potential consumers to click on a given advertisement, and the click is a commonly used measure of potential interest in search engine results. The click through rate (i.e., number of clicks divided by the number of impressions) is one of the most important measures of a sponsored search advertising campaign. As such, any gender differences would shed important light on differentiation in ecommerce advertising.

Hypothesis 03: There will be a significant difference between females and males in the cost per click based on the genderorientation of the query.

Advertisers must bid different amounts for different key phrases depending on the value that they place on those key phrases and the competition from other advertisers. One would expect that key phrases that advertisers expect to garner more clicks would be the most expensive. Therefore, higher cost-per-click for certain key phrases classified along gender lines would indicate preferences by online advertisers.

Hypothesis 04: There will be a significant difference between females and males in the average sales revenue based on the gender-orientation of the query.

Most online advertisements have the aim of generating a sale or lead (i.e., identifying a potential customer). Naturally, gender differences in terms of sales revenue would provide insight into the receptiveness of these searchers to online purchasing and the profitability of these searchers for online advertisers.

Hypothesis 05: There will be a significant difference between females and males in the number of orders based on the gender-orientation of the query.

Related to sales revenue, companies track the number of orders placed for a given set of keywords. Any differences in number of orders among gender key phrases would be an indication of differences in online shopping behaviors, such as willingness to purchase or amount willing to spend.

Hypothesis 06: There will be a significant difference between females and males in the number of items purchased based on the gender-orientation of the query.

Associated with orders, number of items purchased per order is a key metric of online sales. Consumers that purchase multiple items may be more valuable than consumers who purchase only a single item. Gender differences would be of profound importance in several areas of ecommerce.

\section{METHODS}

\section{Overview of Sponsored Search}

In sponsored search campaigns on the major search engines, advertisers bid on key phrases that (1) relate to some product or service that they are providing and that (2) they believe searchers will submit to the search engine. These key phrases provide the link between the results provided from the advertiser and the queries submitted by potential customers, who are the searchers on the Web search engines. When searchers enter queries that match a key phase, the corresponding set of results is displayed on the SERP. Although published data is sparse, reports are that about $15 \%$ of search engine clicks occur on these keyword advertisements [14].

The cost of the ad for the advertiser is determined via an online auction. The exact cost can be in constant flux, as the amount that an advertiser must bid to get an ad to display depends on the overall demand for that key phrase at a given time. The amount that an advertiser is willing to bid depends on the perceived possible value of the customer. Multiple advertisers are typically bidding on the same key phrases simultaneously, so the online auction and bid price can be quite dynamic. However, the search engines provide advertisers an assortment of tools to effectively manage their bids, control risk, and maximize opportunity.

The sponsored results on the SERP are usually shown above the organic results listing (i.e., the north position), to the right of the organic results listing (i.e., the east position), or below the organic results listing (i.e., the south position) depending on the search engine. The sponsored result's rank depends on the bid price, the other bids in the auction, and a quality score (i.e., determined by several factors including bid amount, click through history and landing page relevance to the ad, 
although this varies somewhat by search engine). Therefore, the sponsored search process is an interesting and complex integration of both business process and information technology, making it an interesting system for study.

The sponsored search results are usually textual in nature and normally consist of a short headline, two diminutive lines of text describing the product or service, and a hyperlink that points to the advertiser's landing page (i.e., an advertiser designated Webpage). The predominant keyword advertising model is pay-per-click (PPC), where an advertiser only pays the search engine if a searcher actually clicks on the displayed ad hyperlink.

The entire sponsored search process can be extremely complex, and this brief overview can not do it justice. For the interested reader, there are some good review articles [7, 13] of the sponsored search process.

\section{Data}

The data log used for this research contains daily information on a sponsored search campaign from a large nationwide retail chain that has both a brick and mortar and an online sales presence. This retailer sells a variety of electronic and small household products. The data is a record of the sponsored search advertisement efforts by the company during a 33-month period, spanning 4 calendar years, from 30 September 2005 to 09 June 2008. The log contains a rich data set in that we have the key phrase that triggered the ad, searcher responses, and sales information.

Applicable fields in the log used for the research reported here are shown in Table 1.

Table 1. Fields and Descriptors from Data Log.

\begin{tabular}{|l|l|}
\hline \multicolumn{1}{|c|}{ Field } & \multicolumn{1}{c|}{ Description } \\
\hline Key Phrase & The key phrase that triggered the advertisement \\
\hline Impressions & $\begin{array}{l}\text { The total number of impression for that day for the } \\
\text { given advertisement with the given key phrase }\end{array}$ \\
\hline Clicks & $\begin{array}{l}\text { The number of clicks on the advertisement for that } \\
\text { day for a given key phrase }\end{array}$ \\
\hline Cost & $\begin{array}{l}\text { The total cost for the day for a given key phrase for } \\
\text { a given advertisement }\end{array}$ \\
\hline Orders & $\begin{array}{l}\text { The revenue generated from that advertisement on } \\
\text { that day for a given key phrase }\end{array}$ \\
\hline Items & $\begin{array}{l}\text { The number of orders from the advertisement for } \\
\text { that day for a given key phrase }\end{array}$ \\
\hline & $\begin{array}{l}\text { Number of items purchased from that } \\
\text { advertisement on that day for a given key phrase } \\
\text { from all orders. One order could have one or more } \\
\text { items. }\end{array}$ \\
\hline
\end{tabular}

The log file contains approximately 7 million records from nearly 40,000 key phrases. The data log contains a record for every day in which one of the key phrases triggered an ad. There is a unique record for each key phrase for a given day. Each record in the data log has a variety of information associated by key phrase for a given day. The record includes the key phrase that triggered the ad, number of impressions for that phrase on that day, the number of clicks, the average $\mathrm{CPC}$, the number of conversions (or orders), the total sales revenues, and the total number of items ordered. A query may trigger an impression but no click. If there is a click, there may not be a conversion.

With the exception of Ghose and Yang [8], there have been limited, published empirical studies of sponsored search campaigns using real-world data and none using large-scale datasets. Therefore, we believe our dataset to be a rich source in which to investigate our research question and hypotheses concerning the effect of gender in the sponsored search area.

\section{Gender Classification}

To address our research question, the first step was to classify approximately nearly 40,000 key phrases with some probability of their gender-orientation. To do this, we used the Microsoft adCenter Labs Demographics Prediction Tool (http://adlab.microsoft.com/Demographics-

Prediction/DPUI.aspx). This application takes a given search phrase and provides the probability that the query is male or female-oriented (i.e., provides a probability for both within range of 0 to 1 inclusive).

As stated on the tool's Website, the Demographics Prediction tool helps advertisers learn the demographic-orientation of key phrases before bidding on these terms, with the goal of improving demographic targeting. Hypothetically, with this knowledge, advertisers could determine whether they are reaching their target audience and decide if current keyword bidding is effective. The gender-orientation probabilities are based on a one-month MSN Live Search user online behavior log. Figure 1 shows the Demographics Prediction tool.

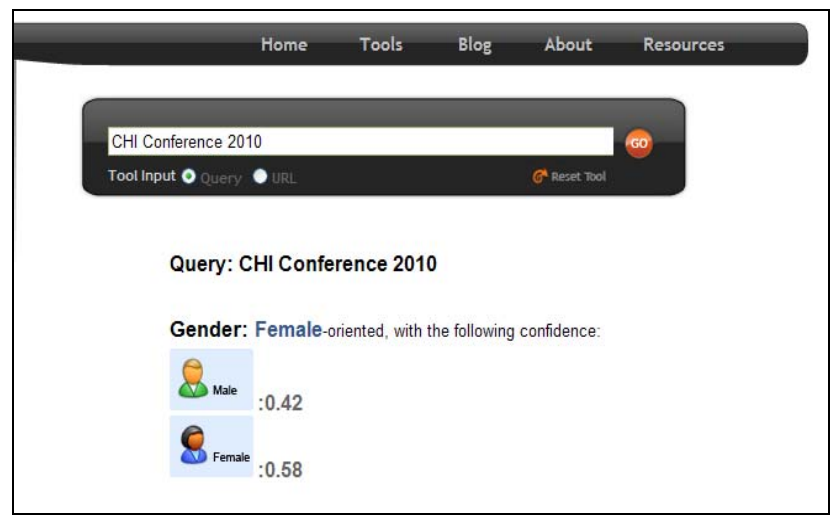

Figure 1: MSN Demographics Prediction tool with Results.

Note that the gender-oriented prediction is specific to the query, not necessarily the searcher. That is, although the gender of the searcher may not be known, the query has a gender-orientation based within a certain confidence interval. The probability confidence is based on Microsoft's predictive model that speculates whether or not a particular query fits gender-specific trends of online behavior based on a log analysis. 
How accurate is the demographic classification? We could locate no published manuscripts addressing this question. However, MSN adCenter Labs has access to large numbers of user profiles (e.g., Hotmail and MSN Passport), so it is a trivial matter to link queries to demographic profiles. Therefore, we expect the accuracy of the gender classification tool to be high.

Using this tool, we classified the nearly 40,000 key phrases in the data set for gender-orientation using an automated script that submitted the query and then retrieved the genderorientation probabilities.

For this research, we devised seven categories of genderorientation classification strength based on the probability returned by the MSN adCenter Labs predictive model. The seven categories, a probability range, and example key phrases are given in Table 2.

Table 2. Gender Classification Categories.

\begin{tabular}{|c|c|c|}
\hline $\begin{array}{c}\text { Gender } \\
\text { Classification }\end{array}$ & $\begin{array}{l}\text { Probability } \\
\text { Range }\end{array}$ & $\begin{array}{c}\text { Example of Key Phrases in } \\
\text { Category }\end{array}$ \\
\hline Really Male & $\begin{array}{l}1.00 \text { to }>0.85 \\
\text { (Male) }\end{array}$ & $\begin{array}{l}\text { electronic chess } \\
\text { blue tooth wireless headsets }\end{array}$ \\
\hline $\begin{array}{l}\text { Generally } \\
\text { Male }\end{array}$ & $\begin{array}{l}0.85 \text { to }>= \\
0.75 \text { (Male) }\end{array}$ & $\begin{array}{l}\text { cool automotive lights } \\
\text { self-powered radios }\end{array}$ \\
\hline Leaning Male & $\begin{array}{l}0.75 \text { to }>= \\
0.60 \text { (Male) }\end{array}$ & $\begin{array}{l}\text { blue mini ipod } \\
\text { shake flash light }\end{array}$ \\
\hline $\begin{array}{l}\text { Gender } \\
\text { Neutral * }\end{array}$ & $\begin{array}{l}0.60>\text { (Male) } \\
\&<0.60 \\
\text { (Female) }\end{array}$ & $\begin{array}{l}\text { clock radio } \\
\text { silent air purifier }\end{array}$ \\
\hline $\begin{array}{l}\text { Leaning } \\
\text { Female }\end{array}$ & $\begin{array}{l}0.75 \text { to }>= \\
0.60 \text { (Female) }\end{array}$ & $\begin{array}{l}\text { quality bathroom lights } \\
\text { bed bath devices }\end{array}$ \\
\hline $\begin{array}{l}\text { Generally } \\
\text { Female }\end{array}$ & $\begin{array}{l}0.85 \text { to }>= \\
0.75 \text { (Female) }\end{array}$ & $\begin{array}{l}\text { special kitty bowls } \\
\text { presents for dads day }\end{array}$ \\
\hline Really Female & $\begin{array}{l}1.00 \text { to }>= \\
0.85 \text { (Female) }\end{array}$ & $\begin{array}{l}\text { talking photo album } \\
\text { unique christmas presents }\end{array}$ \\
\hline
\end{tabular}

* Note that the Gender Neutral category is twice as large.

From Table 2, of the seven categories, there were three male, three female, and one gender neutral. The gender specific categories represents $10-15$ percent of the entire probability range, with Gender Neutral representing the largest range (20\%) and Generally Male and Generally Female the smallest (10\%) each. All other categories were $15 \%$ of the probability range. Our classification into these seven categories was designed to both tease apart the levels of gender-orientation personalization and make the results usable for practitioners in the field. Our selection of exact ranges for each category was somewhat arbitrary; however, it appears that people are best able to perceive probabilities in five and ten scale increments [2].

The occurrences for each category for the nearly 40,000 unique phrases are shown in Table 3 . We see from Table 3 that $39 \%$ of the key phrases were oriented male (i.e., Really Male, Generally Male, and Leaning Male). There were 36\% of the key phrases that were oriented female (i.e., Really Female, Generally Female, and Leaning Female). So, the gender-orientation was roughly in balance.
Table 3. Gender Classification of Key Phrases.

\begin{tabular}{|l|r|r|}
\hline Gender Classification & \multicolumn{1}{|c|}{ Occurrences } & \multicolumn{1}{c|}{ \% } \\
\hline Really Male & 4,322 & $10.9 \%$ \\
\hline Generally Male & 3,738 & $9.4 \%$ \\
\hline Leaning Male & 7,601 & $19.2 \%$ \\
\hline Gender Neutral & $\mathbf{9 , 5 1 7}$ & $\mathbf{2 4 . 1 \%}$ \\
\hline Leaning Female & 8,133 & $20.6 \%$ \\
\hline Generally Female & 4,515 & $11.4 \%$ \\
\hline Really Female & 1,735 & $4.4 \%$ \\
\hline & 39,561 & $100.0 \%$ \\
\hline
\end{tabular}

Note: Highest percentage is bolded.

\section{Data Analysis}

Once each unique key phrase was classified, we used this set of queries to automatically classify the nearly 7 million records in the complete dataset. Once this was accomplished, we could then link each key phrase, now classified into one of the gender-orientation categories, to the associated user behavioral and sales data. Once done, we could then examine each key phrase occurrence based on our research question and hypotheses. A snippet of records from the data log showing applicable fields is shown in Table 4.

Table 4. Snippet From Data Log Showing Applicable Fields.

\begin{tabular}{|c|c|c|c|c|c|c|}
\hline 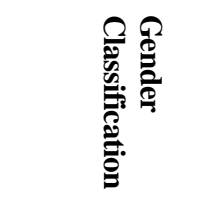 & 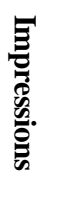 & $\stackrel{\rho}{\overline{\bar{\alpha}}}$ & คి & 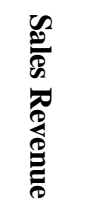 & $\begin{array}{l}0 \\
\frac{0}{2} \\
\frac{2}{6}\end{array}$ & 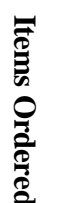 \\
\hline Generally Male & 5 & 1 & 0.20 & 49.95 & 1 & 1 \\
\hline Gender Neutral & 37 & 3 & 0.45 & 29.95 & 1 & 3 \\
\hline Really Female & 10 & 5 & 0.26 & 9.96 & 3 & 6 \\
\hline Gender Neutral & 2 & 1 & 0.10 & 56.01 & 1 & 4 \\
\hline
\end{tabular}

\section{RESULTS}

\section{Gender-Orientation Classification}

Using the nearly 40,000 queries labeled in gender-orientation categories, we automatically categorized the entire approximately seven million query dataset, with findings presented in Table 5.

Table 5. Gender Classification of Key Phrases in Dataset.

\begin{tabular}{|l|r|r|}
\hline Gender Classification & Occurrences & \multicolumn{1}{c|}{ \% } \\
\hline Really Male & 804,896 & $11.7 \%$ \\
\hline Generally Male & 824,850 & $12.0 \%$ \\
\hline Leaning Male & $1,539,031$ & $22.4 \%$ \\
\hline Gender Neutral & $\mathbf{1 , 9 2 2 , 1 0 6}$ & $\mathbf{2 8 . 0 \%}$ \\
\hline Leaning Female & $1,141,424$ & $16.6 \%$ \\
\hline Generally Female & 446,134 & $6.5 \%$ \\
\hline Really Female & 185,740 & $2.7 \%$ \\
\hline & $6,864,181$ & $100.0 \%$ \\
\hline
\end{tabular}

Note: Highest percentage is bolded. 
Comparing Table 3 (i.e., unique key phrases) and Table 5 (i.e., key phrases occurring in total dataset), we see that the percentages are generally similar. The only difference in ranking between the two data samples that is a swap between Leaning Female (the second most frequent key phrase) and Leaning Male (the third most frequent key phrase), based on occurrences in the entire dataset. A Spearman's rank correlation coefficient test found no significant difference between the two rankings, indicating that the key phrases for the search engine marketing campaign are inline with the expressed interests of the online consumers.

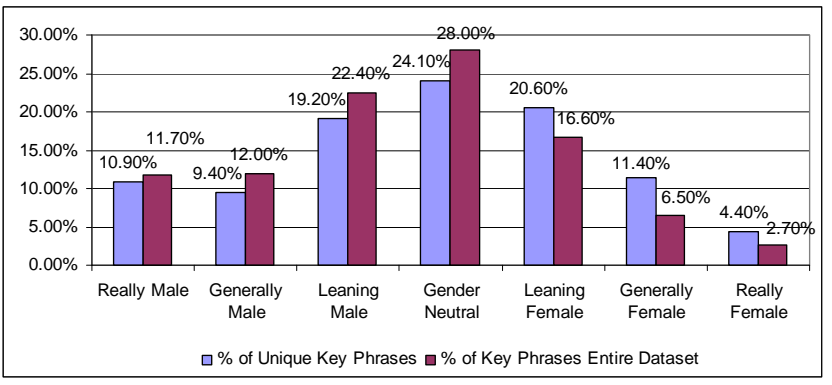

Figure 2: Comparison of Key Phrases Occurrences.

Examining the comparison graphically, as is shown in Figure 2 , the female-oriented queries are generally over represented in the set of unique key phrases relative to the overall dataset.

\section{Hypotheses Testing}

In evaluating our six hypotheses, we used a one-way ANOVA statistical analysis to compare means and variance between the groups. The one-way ANOVA tests whether two or more groups are significantly different. For all ANOVA tests presented, the critical value of $F=3.78$.

Hypothesis 01: There will be a significant difference between male and female in the number of impressions based on the gender-orientation of the query.

The results indicate that there is a significant difference among the categories $(\mathrm{F}(6)=1,857.84, \mathrm{p}<0.01)$. The Tamhane's T2 Test indicated a significant difference among all seven gender classifications. Therefore, hypothesis 01 is fully supported.

Table 6. Impressions by Gender Classification.

\begin{tabular}{|l|r|r|}
\hline \multicolumn{1}{|c|}{ Gender Classification } & \multicolumn{1}{|c|}{ Mean } & \multicolumn{1}{c|}{ St Dev } \\
\hline Really Male & 29.37 & 549.73 \\
\hline Generally Male & 32.09 & 203.36 \\
\hline Leaning Male & 49.57 & 409.80 \\
\hline Gender Neutral & $\mathbf{1 0 7 . 7 5}$ & $\mathbf{1 , 2 6 2 . 8 3}$ \\
\hline Leaning Female & 54.21 & 422.29 \\
\hline Generally Female & 38.11 & 366.43 \\
\hline Really Female & 36.40 & 254.44 \\
\hline All Categories & 61.06 & 752.11 \\
\hline \multicolumn{2}{|c|}{ Note: Highest mean value is bolded. $\mathrm{p}<0.05$ for all Tamhane's T2 Test }
\end{tabular}

From Table 6, we see that the mean number of impressions was just more than 61 for all gender-classifications.
However, the mean is skewed due to the extremely high mean number of impressions for key phrases with a gender neutral orientation. All other categories were below the overall mean. We also note that female-oriented key phrases generated more impressions than the corresponding maleoriented categories.

This would indicate that prior reports of females being less inclined to shop online [c.f., 23] may no longer be valid.

Hypothesis 02: There will be a significant difference in the number of clicks based on the gender-orientation of the query.

The results indicate that there is a significant difference among the categories $(F(6)=1,239.26, \mathrm{p}<0.01)$. The Tamhane's T2 Test indicated a significant difference among all seven gender classifications. Therefore, hypothesis 02 is fully supported.

From Table 7, we see that the mean number of clicks overall is 1.93 clicks per occurrence of a key phrase. However, the mean is again skewed due to the Gender Neutral, with a mean number of clicks of 4.17. All other categories were below the overall mean. Combined with the higher rate of impression, this would indicate that not only are females conducting online ecommerce searching, they are willing to engage in online advertising.

Table 7. Clicks by Gender Classification.

\begin{tabular}{|l|r|r|}
\hline Gender Classification & Mean & \multicolumn{1}{|c|}{ St Dev } \\
\hline Really Male & 0.51 & 3.82 \\
\hline Generally Male & 0.72 & 4.07 \\
\hline Leaning Male & 1.14 & 12.14 \\
\hline Gender Neutral & $\mathbf{4 . 1 7}$ & $\mathbf{8 0 . 5 8}$ \\
\hline Leaning Female & 1.59 & 12.19 \\
\hline Generally Female & 0.97 & 6.84 \\
\hline Really Female & 1.16 & 15.74 \\
\hline All Categories & 1.93 & 43.49 \\
\hline
\end{tabular}

Note: Highest mean value is bolded. $\mathrm{p}<0.05$ for all Tamhane's T2 Test

Hypothesis 03: There will be a significant difference in the cost per click based on the gender-orientation of the query.

The results indicate that there is a significant difference among the categories $(\mathrm{F}(6)=6,792.20, \mathrm{p}<0.01)$. The Tamhane's T2 Test indicated a significant difference among all seven gender classifications. Therefore, hypothesis 03 is fully supported.

From Table 8, our pattern that we saw with impressions and clicks does not hold with CPC. The mean CPC for both Gender Neutral (0.70) and Leaning Male (0.85) oriented key phrases were the highest mean CPC, and the other five categories lower than the overall mean. Although, we saw earlier that the female-oriented key phrases generated more impression and clicks, the CPC is higher for two of the male oriented categories relatively to the corresponding femaleoriented categories. 
Table 8. CPC by Gender Classification.

\begin{tabular}{|l|r|r|}
\hline \multicolumn{1}{|c|}{ Gender Classification } & Mean (\$) & St Dev (\$) \\
\hline Really Male & 0.43 & 0.52 \\
\hline Generally Male & 0.59 & 0.83 \\
\hline Leaning Male & $\mathbf{0 . 8 5}$ & $\mathbf{1 . 0 8}$ \\
\hline Gender Neutral & 0.70 & 0.91 \\
\hline Leaning Female & 0.53 & 0.57 \\
\hline Generally Female & 0.51 & 0.48 \\
\hline Really Female & 0.51 & 0.52 \\
\hline All Categories & \multicolumn{2}{|c|}{0.65} \\
\hline \multicolumn{2}{|c|}{ Note: Highest mean value is bolded. $p<0.05$ for all Tamhane’s T2 Test } \\
\hline
\end{tabular}

Advertisers have an incentive to bid higher on the key phrases that convert more customers. So, these higher CPC would indicate that, regardless of the number of impressions or clicks, the advertisers consider these potential customers (i.e., those searching with key phrases of Gender Neutral, Leaning Male, and Generally Male orientation) of higher value, which is reflected in the higher CPC for these genderoriented categories.

Hypothesis 04: There will be a significant difference in the average sales revenue based on the gender-orientation of the query.

The results indicate that there is a significant difference among the categories $(\mathrm{F}(6)=272.63, \mathrm{p}<0.01)$. The Tamhane's T2 Test indicated a significant difference among all seven gender classifications. Therefore, hypothesis 04 is fully supported.

Table 9.Sales Revenue by Gender Classification.

\begin{tabular}{|l|r|r|}
\hline \multicolumn{1}{|c|}{ Gender Classification } & Mean (\$) & St Dev (\$) \\
\hline Really Male & 0.80 & 70.95 \\
\hline Generally Male & 0.97 & 20.30 \\
\hline Leaning Male & 2.34 & 46.51 \\
\hline Gender Neutral & $\mathbf{2 3 . 3 1}$ & $\mathbf{7 0 5 . 5 1}$ \\
\hline Leaning Female & 4.69 & 94.93 \\
\hline Generally Female & 1.64 & 46.48 \\
\hline Really Female & 1.44 & 31.21 \\
\hline All Categories & 8.19 & 377.22 \\
\hline \multicolumn{2}{|c|}{ Note: Highest mean value is bolded. $p<0.05$ for all Tamhane’s T2 Test }
\end{tabular}

We see from Table 9 that the Gender Neutral oriented key phrases generated far more average sales revenue than any other category. We also see that the female-oriented key phrases generate more average revenue than the corresponding male-oriented categories.

This would indicate that, based on sales revenue, the higher CPCs for the male-oriented key phrases are not justified, as the female-oriented phrases generate higher sales revenue.

Hypothesis 05: There will be a significant difference in the number of orders based on the gender-orientation of the query.

The results indicate that there is a significant difference among the stages $(\mathrm{F}(6)=599.04, \mathrm{p}<0.01)$. The Tamhane's T2 Test indicated a significant difference among all seven gender classifications. Therefore, hypothesis 05 is fully supported.

From Table 10, the highest mean was, again, the Gender Neutral oriented queries, with a mean order of 0.15 per query. The male and female oriented queries were balanced at the Generally Female and Generally Male.

Table 10. Orders by Gender Classification

\begin{tabular}{|l|r|r|}
\hline \multicolumn{1}{|c|}{$\begin{array}{c}\text { Gender } \\
\text { Classification }\end{array}$} & \multicolumn{1}{c|}{ Mean } & \multicolumn{1}{c|}{ St Dev } \\
\hline Really Male & $\sim 0.00$ & 0.15 \\
\hline Generally Male & 0.01 & 0.12 \\
\hline Leaning Male & 0.02 & 0.232 \\
\hline Gender Neutral & $\mathbf{0 . 1 5}$ & $\mathbf{4 . 9 2}$ \\
\hline Leaning Female & 0.04 & 0.65 \\
\hline Generally Female & 0.01 & 0.14 \\
\hline Really Female & 0.02 & 0.31 \\
\hline All Categories & 0.05 & 2.62 \\
\hline \multicolumn{2}{|c|}{ Note: Highest mean value is bolded. $\mathrm{p}<0.05$ for all Tamhane's T2 Test }
\end{tabular}

Hypothesis 06: There will be a significant difference in the number of items purchased based on the gender-orientation of the query.

The results indicate that there is a significant difference among the stages $(\mathrm{F}(6)=548.80, \mathrm{p}<0.01)$. The Tamhane's T2 Test indicated a significant difference among all seven gender classifications. Therefore, hypothesis 06 is fully supported.

Table 11. Items Sold by Gender Classification.

\begin{tabular}{|l|r|r|}
\hline Gender Classification & Mean & St Dev \\
\hline Really Male & 0.01 & 0.27 \\
\hline Generally Male & 0.01 & 0.24 \\
\hline Leaning Male & 0.03 & 0.44 \\
\hline Gender Neutral & $\mathbf{0 . 2 8}$ & $\mathbf{9 . 7 2}$ \\
\hline Leaning Female & 0.07 & 1.30 \\
\hline Generally Female & 0.02 & 0.34 \\
\hline Really Female & 0.03 & 0.64 \\
\hline All Categories & \multicolumn{2}{|c|}{0.10} \\
\hline \multicolumn{2}{|c|}{ Note: Highest mean value is bolded. $p<0.05$ for all Tamhane's T2 Test }
\end{tabular}

From Table 11, we see that the Gender Neutral oriented key phrases had the highest mean number of items sold (0.28). The female-oriented key phrases had a higher mean number of items sold than the corresponding male-oriented phrases.

\section{DISCUSSION AND IMPLICATIONS}

\section{Discussion of Results}

In this research, we investigated the gender-orientation of key phrases as an aspect of human information processing and personalization. Traditional wisdom would hold that increased personalization will lead to a better online experience for the searcher, thereby leading to increased revenue for the advertiser. The research results from our study indicate that increased gender-oriented key phrases are more expensive and do not generate increase sales revenue. In fact, by all metrics examined, the key phrases that were 
gender neutral performed the best overall. In other words, the key phrases that were less personalized performed better.

The gender neutral key phrases generated nearly twice as many impressions as any other category of key phrases and nearly two and half times as many clicks. So, not only are these gender neutral phrase the most searched for (i.e., more impressions), they are the ones most clicked on (i.e., have the most consumer interest).

Although, the gender neutral key phrases are the second most expensive (trailing Leaning Male by 21\%), they generated far and away the most sales revenue, beating the nearest other category (Leaning Female) by a factor of nearly five. Continuing, these gender neutral queries generate four times the orders of the nearest other category (again Leaning Female) and also four times as many items ordered. All in all, gender neutral-oriented queries appear to be the best performing by any of the standard keyword advertising metrics.

However, there were also some interesting findings when comparing the male and female oriented key phrases. The female-oriented key phrases generated about $10 \%$ to $20 \%$ more impressions and approximately $40 \%$ to $127 \%$ more clicks than the male oriented key phrases. Obviously, the female-oriented key phrases are triggering more ads, and the searchers submitting these female-oriented queries are engaging more with the resulting ads than searchers submitting male-oriented queries.

Additionally, these female-oriented key phrases generated $70 \%$ to $100 \%$ more mean sales revenue than the analogous male-oriented key phrases, with nearly the same mean number of orders (although Leaning Female key phrases are higher them the Leaning Male phrase). This would imply that the searchers with female-oriented queries are making more expensive orders. This is also borne out in the number of items ordered, with the average number of items ordered for female-oriented key phrase $100 \%$ to $200 \%$ higher than maleoriented phrase. These factors would indicate that, aside from gender neutral ones, female-oriented key phrases are the most valuable, given they generate the most sales. However, this is not reflected in the mean CPC for these key phrases, as illustrated in Figure 3.

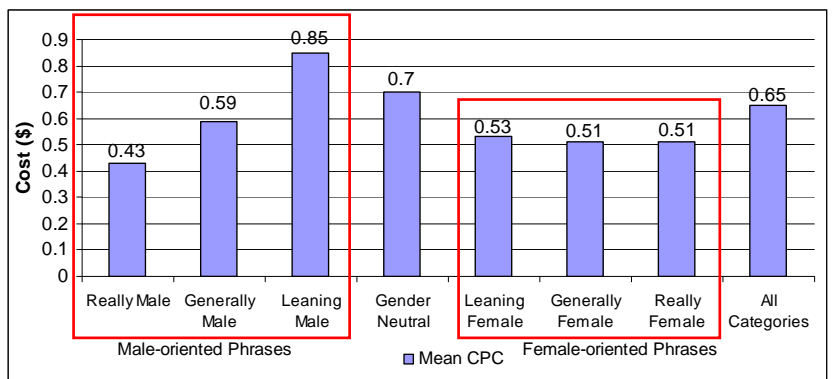

Figure 3: Comparison of Mean CPC by Gender Classification.
From Figure 3, the category with the highest mean CPC is Leaning Male key phrases, even though this category is the only the third ranked in terms of sales revenue generation (trailing Gender Neutral by a factor of ten and Leaning Female by a factor of two). Also, the Generally Male key phrases category is the third most expensive, then though it trails all female-oriented key phrase categories in sales revenue. Obviously, from a gender-orientation perspective, the higher mean CPCs for the Leaning Male and Generally Male are not justified relative to their sale generation.

Through gender classification, these research findings point to an inconsistency in spending on keyword advertising phrase in relation to the measurable results that these phrases are generating.

\section{Theoretical Implications}

In terms of human information processing, it appears that our findings do support prior work indicating differences in the way that males and females gather and process information. With SERPs containing both organic and sponsored results, there is a choice of information types available. Females appear more willing to click on sponsored results, as indicated by the higher click through rates on femaleoriented phrases. This conforms to earlier information processing research indicating that females are more willing to consider a range of information sources.

While men's decision-making tends to be systematic, women's decision-making is less linear and puts more factors into consideration [9]. So, if an advertiser considers gender targeting critical to their online business, it is necessary to incorporate these differences in information processing into their advertising.

The theory of social categories [6], the basis of personalization in this area, would indicate the genderoriented phrase should have performed better. What could account for this perhaps unexpected outcome? An answer might lie in the theory of individual differences [19], which posits that an individual responses to information according to unique cognitive, affect, psychological, and contextual needs. In such a complex interplay, such as online commerce, gender may just not be a dominant factor in predicting behavior. Trauth has noted similar findings with gender and information technology [25].

\section{Practical Implications}

Even though our findings are statistically significant, one must ask, "are these differences of practical significance?". Based on the findings from this research study, the gender neutral key phrases are the most successful in snatching interested searchers (i.e., impressions) and potential customers (i.e., those searchers who click on a sponsored result). The gender neutral key phrases are also the most profitable, generating the most sales revenue, orders, and items ordered. While this may seem somewhat counter 
intuitive (i.e., what if one is selling a gender-specific product?), beyond a few specialty items (e.g., personal hygiene, etc.), so many items can be 'gifted' that demographic targeting can be counter productive (i.e., more expensive and less profitable). Additionally, given individual differences, gender may just be too coarse of a discriminatory factor for keyword advertising.

Of the key phrases that are gender-oriented, the femaleoriented ones appear to be the most fruitful area to pursue. The female-oriented key phrases generate more impressions and clicks, relative to the male-oriented phrases. The femaleoriented phrases also generate significantly more sales revenue, orders, and items sold. Also, the female phrases generate this advertising success while being generally cheaper than the corresponding male-oriented phrases. So, if an advertiser was to gender target key phrases, these findings would indicate that female-oriented phrases might be the more fruitful area for demographic targeting.

On the other hand, the male-oriented key phrases include some of the most expensive average CPC, significantly more expensive than even the gender-neutral phrases. Given their high CPC and relatively lower performance, demographic targeting male-oriented key phases might not be a fertile endeavor. However, we must caveat this by saying that sponsored search is a multi-variable process. These maleoriented phrases may be associated with some other advertising goal, such as brand awareness or image. However, in terms of sales, they are not generating revenue in line with their relative CPCs.

These results also point to possible design implications for sponsored search technology platforms and services. Many of these permit demographic targeting of advertisements that display on Websites (a.k.a., known as content advertising). However, none that the authors could determine permitted gender targeting of keyword advertisements. Such a feature, triggered by a method similar to that used in this research, would allow advertisers to rotate ads based on the genderfocus of the query, rather than just by key phases.

\section{Limitations and Strengths}

As with any research, there are limitations to our study. First, the data set is from one retail company. Although the dataset is quite large both in terms of number of records and temporal span, one will need additional research using data from other companies and other industry sectors to ensure generalizeable results to these other areas. Nevertheless, we believe that the research reported in this study is an important step in the empirical research of demographic targeting in the sponsored search area. Second, the dataset used in this research does not contain the customer behaviors on the Web landing pages or the offline behaviors of the searchers. Customers may be using Web search engines for some portions of the purchasing process and then using alternative information systems sources for other portions, and this behavior may vary by gender. However, at least for the behaviors on the search engine, the findings reported here seem to support gender-oriented differences. Finally, the accuracy of the MSN gender tool has not been independently verified. However, the distribution of gender-neutral to gender-specific keywords was what one would expect, so the tool's results are at least within expectations.

This research also has several strengths. Based on the significance of the findings, we believe that the research results discussed here make valuable contributions to the small but growing research in the important sponsored search area, with implications for information seeking, marketing, and advertising. Given the substantial impact that sponsored search technology and its related business process has had in the development and growth of the Web and online commerce, it is an area that deserves extensive investigation.

As an additional strength of this research, the data set was quite substantial, with nearly seven million records and of a lengthy data collection period (i.e., 33 months spanning four calendar years). The dataset also includes a varied set of search and consumer behavior and interactions (e.g., impressions, clicks, orders place, items ordered, and money spent). Therefore, the research findings provide important insights into behavior in the real world, online commercial domain.

\section{CONCLUSION}

The results of this research conclude that gender-oriented key phrases do not generate more sales but can cost more for advertisers relative to gender-neutral queries. Generally, it is beneficial for online advertisers to devote resources targeting these gender neutral key phrases. For future work, investigating the gender perception of online advertisements over time could lead, perhaps, to better advertisement creation. This could increase the receptiveness of the ads and in turn enhance the overall effectiveness of a campaign.

\section{ACKNOWLEDGMENTS}

Our thanks to The Rimm-Kaufman Group, particularly George Michie, for providing data for this study and to Steve Carman for the web scrapping. Dr. Jansen acknowledges a gift from Google and a grant from the Air Force Office of Scientific Research in support of portions of this research. We also acknowledge and thank Alan Rimm-Kaufman, who departed this world on 18 July 2009.

\section{References}

1. Anick, P., Using Terminological Feedback for Web Search Refinement - A Log-Based Study. in Twenty-Sixth Annual International ACM SIGIR Conference on Research and Development in Information Retrieval, (Toronto, Canada, 2003), 88-95.

2. Ayres, I., Ayres-Brown, A. and Ayres-Brown, H. Seeing Significance: Is the 95\% Probability Range Easier to Perceive? Chance, 20 (11) (2007). 11-17. 
3. Baron-Cohen, S. The essential difference: The truth about the male and female brain. Basic Books, New York, NY, 2004.

4. Blom, J., Personalization: a taxonomy. in $\mathrm{CHI}$ 'OO extended abstracts on Human factors in computing systems, (The Hague, The Netherlands, 2000), 313 - 314.

5. Chen, V. (2009, 14 January). Behavioral Targeting and the Gender Divide. Retrieved 1 September, 2009, from http://www.clickz.com/3632342

6. Deaux, K. From Individual Differences to Social Categories. Analysis of a Decade's Research on Gender. American Psychologist, 39 (2) (1984). 105-116.

7. Fain, D.C. and Pedersen, J.O. Sponsored Search: A Brief History. Bulletin of the American Society for Information Science and Technology, 32 (2) (2006). 12-13.

8. Ghose, A. and Yang, S., An Empirical Analysis of Sponsored Search Performance in Search Engine Advertising. in First ACM International Conference on Web Search and Data Mining (WSDM 2008), (Palo Alto, California, 2008), 241-250

9. Hanson, S. (2009, January). Beyond pink Retrieved 3 September, 2009, from http://www.director.co.uk/magazine/2009/1\%20Jan/mark eting_women_62_6.html

10. Horrigan, J.B. Online Shopping, Pew Internet \& American Life Project, Washington. D.C., 2008, 32.

11. Ibanez, M., Czermak, S. and Sutter, M. Searching for a better deal - On the influence of group decision making, time pressure and gender on search behavio. Journal of Economic Psychology, 30 (1) (2009). 1-10.

12. Jansen, B.J. and Kroner, G., The Impact of Automated Assistance on the Information Retrieval Process. in The ACM CHI 2003 Conference on Human Factors in Computing Systems, (Fort Lauderdale, Florida, 2003), 1004 - 1006.

13. Jansen, B.J. and Mullen, T. Sponsored search: An overview of the concept, history, and technology. International Journal of Electronic Business, 6 (2) (2008). $114-131$.

14. Jansen, B.J. and Spink, A. Investigating customer click through behaviour with integrated sponsored and nonsponsored results. International Journal of Internet Marketing and Advertising, 5 (1/2) (2009). 74-94.

15. Large, A., Beheshti, J. and Rahman, T. Gender differences in collaborative web searching behavior: an elementary school study. Information Processing and Management, 38 (3) (2002). 427-443.

16. Lorigo, L., Pan, B., Hembrooke, H., Joachims, T., Grank, L. and Gay, G. The influence of task and gender on search and evaluation behavior using Google.

Information Processing and Management, 42 (4) (2006). 1123-1133.

17. McMahan, C., Hovland, R. and McMillan, S., Gender and Internet Advertising: Differences in the Ways Males and Females Engage and Perceive Internet Advertising. in American Academy of Advertising Conference, (Lubbock, Tx, 2008), 52-55.

18. Meyers-Levy, J. Influence of sex roles on judgement. Journal of Consumer Research, 14 (4) (1988). 522-530.

19. Motowidlo, S.J., Borman, W.C. and Schmit, M.J. A theory of individual differences in task and contextual performance. Human Performance, 10 (1) (1997). 71-83.

20. Okazaki, S. Exploring gender effects in a mobile advertising context: on the evaluation of trust, attitudes, and recall. Sex Roles, 57 (11/12) (2007). 897-908.

21. Phillip, M.V. and Suri, R. Impact of gender differences on the evaluation of promotional emails. Journal of Advertising Research, 44 (4) (2004). 360-368.

22. Putrevu, S. Exploring the origins and information processing differences between men and women: implications for advertisers. Academy of Marketing Science Review, 10 (1) (2002). Article 1.

23. Rodgers, S. and Harris, M.A. Gender and e-commerce: an exploratory study. Journal of Advertising Research, 43 (1) (2003). 322-329.

24. Roy, M. and Chi, M.T.H. Gender differences in patterns of searching the web. Journal of Educational Computing Research, 29 (3) (2003). 335-348.

25. Trauth, E.M. Odd girl out: an individual differences perspective on women in the IT profession. Information Technology \& People, 15 (2) (2002). 98-118.

26. Wilson, T.D. Human Information Behavior. Informing Science, 3 (2) (2000). 49 - 55.

27. Wolin, L.D. and Korgaonkar, P. Web advertising: gender differences in beliefs, attitudes and behavior. Internet Research: Electronic Networking Applications and Policy, 13 (5) (2003). 375-385. 